\title{
Construction reorganization as a type of high- rise construction and environmental protection
}

\author{
Robert Avetisyan ${ }^{1, *}$, Muhammad Khalil ${ }^{1}$, Natalya Galaeva ${ }^{1}$, and Ruben Kazaryan ${ }^{1}$ \\ ${ }^{1}$ Moscow State University of Civil Engineering, 129337, Yaroslavskoe shosse, 26, Moscow, Russia
}

\begin{abstract}
Construction reorganization, as a type of high-rise construction is part of a basic reorganization cycle in which four phases (phases, states, technological redistribution) are consistently implemented: device, disorganization, reorganization and co-organization. Loft style methodology: the integrated performance indicator organizational and technological operational reliability (OTOR) of the Loft room, which is determined with the help of stellar infographic models, makes it possible to prove arguably the necessity or absence of the need to reorganize the former industrial building. The assessment of the functional zone of the level of the OTOR indicators in the system of the infographic model, in which the number of axes emanating from the point "zero", corresponds to the number of parameters characterizing a specific functional zone. Valuation parameters are ranked in accordance with their tendency towards centripetal and centrifugal. The field of our research lies in the phase of reconstruction. The determination of the level of OTOR of one functional zone is formed by the construction of two infographic star-shaped models, one of which is constructed by centripetal indicators, and the other by centrifugal indicators.
\end{abstract}

\section{Introduction}

Hinged systems for finishing buildings and structures are a combination of structures and connections developed on the basis of unification and standardization of their general forms and sizes, spatial planning, organizational, technological and design solutions that imply the possibility of "assembling and disassembling" the structure both locally and Replacement in general.

The following are referred to the retreat: [1, 2]:

- the device of ventilated facades with a vertical arrangement of guides and lining of facade cassettes, with porcelain tiles, with lining of fiber cement slabs, with facing from profiled sheets, with facade siding lining;

- the device of cold facades (outer layer - glass panels, and the function of thermal insulation is the construction of the wall of the building, on which the outer layer is fixed with an air gap);

\footnotetext{
*Corresponding author: robert.avetisyan.98@mail.ru
} 
- the device of the exhaust façade (outer layer - glass packet plus glass, installed at a distance of 15-20 cm from the double-glazed window, with the air gap being used either for air extraction and ventilation of the building, or for heating the fresh air intake);

- structural glazing device (a method of combining glass, ceramics and metal in one design using special adhesive silicone sealants);

- hinged systems for interior decoration of the building (raised floor, ceiling, walls), etc.;

- automated systems for ensuring the integrated security of buildings and structures;

- Loft style appliances;

- installation of attic rooms from materials that do not provide reinforcement of loadbearing structures and foundations;

- Adding an attic without a truss structure and measures to strengthen the foundation with MDM boards (polystyrene foam, penetrated with plaster mesh), which are installed in the required position, covered with concrete plaster on both sides, and then on top - with roofing material.

One of the most striking examples of retreatment of a dwelling is the Loft style.

Loft style appeared in America in the late 20-ies of the last century and at first in the category of elite housing did not fall. The English word loft, meaning "loft" or "top floor" of an industrial building, gave the name to a specific kind of residential real estate apartments located in the buildings of former factories and plants. In most cases, apartments are located, starting from the second floor or directly in the attic, while the first floor of the building is occupied by office and commercial premises or converted to a studio or gallery.

Initially, this style attracted artists and people of creative professions. Large spacious room, high ceilings, huge windows, mixing old (brick or concrete walls, pipes) and new (glass and metal surfaces) materials. After all, it is the industrial elements that are the unique attribute of this style, bringing the "industrial" atmosphere to the image of the apartment.

\section{Methods}

Distinctive features of the Loft style:

- dwellings of this type are created in former production premises with an area of 200$1000 \mathrm{~m} 2$ with a minimum number of load-bearing structures and partitions;

- many loft-style rooms represent one huge room (only bathrooms are allocated), while in others one or several bedrooms are fenced off;

- the prerequisite is the principle of zoning space, solely with the color and texture of the materials;

- there is also a vertical zoning - if the Loft-room has several levels, on the upper mezzanines there is a territory for personal use of the owner and his near circle;

- characteristic feature of the "loft" are unplastered brick walls; If initially there are no such surfaces in the room, the walls are often faced with specially aged masonry;

- If the building is made of concrete, then in some places it is necessary to leave rough concrete walls and cement floors;

- The second dominant material is metal, from which not only the ventilation and water pipes are made, which are generally accepted for display in the lofts, but also a significant part of the furniture (chic columns, concrete beams, floor From rough boards, and sometimes even the remains of machine tools, designed as art objects);

- The third material of the loft is glass: giant (floor-to-ceiling) windows, glass furniture (as if hanging in the air against a dark brick background), a few partitions of bedrooms and bathrooms from glass blocks; 
- organization of the space in such a way that light, penetrating the room from all sides, creates a sense of transparency;

- metal plates as a floor covering of the kitchen area (very popular are the antique cast iron plates of the 19th century); In residential areas often use parquet; Halls and stairs can be finished with a polished stone or marble tiles;

- often architects and artists combine business with pleasure, organizing an exhibition of their works in the Loft or a studio-workshop. Collectors place in such rooms a collection of paintings, sculptures or antique furniture, and restrained colors and the absence of small details serve as the best background for works of art of any style.

In the organization of this style there are components of retracement (type of building reconstruction) - hinged finishing systems.

The premise that previously had a factory or factory assignment is rearranged using hinged finishing systems, that is, the whole building is connected to the existing building for further joint work, assuming a quick replacement of the system both locally and in general.

In apartments "Loft" the following hinged systems are used: window-windows; Metal beams and pipes; Glass partitions, glass blocks; Flooring - metal plates, cast-iron plates, parquet, stone and tiles; Hinged glass facades from floor to ceiling, etc.

\section{Results}

Examples of European lofts that exist in the format of cultural centers that rent part of their premises for offices, showrooms, restaurants, studios, dance studios, etc., are CABLE FACTORY in Helsinki, MELKWEG in Amsterdam, TEA FACTORY in London, SUPERSTUDIO in Milan.

Recently in Moscow a new unique project was launched - the reconstruction of the chocolate factory "Red October", built in 1867. The complex is located in an extremely advantageous location - on the only island in Moscow, and from the windows of future elite apartments will open a view of the Moscow River, the Kremlin and the Cathedral of Christ the Savior. Objects recognized as architectural monuments - two production buildings and the building of the Imperial Yacht Club, as well as six objects of particularly valuable historical buildings - will be carefully preserved and reconstructed. In total, over 170 thousand $\mathrm{m} 2$ of elite residential and commercial real estate, including infrastructure such as cafes, restaurants, parking, fitness center, gastronomy, should appear in the territory of Red October for several years. At present, the general planning of the whole complex is completed and the architectural concept of development is being developed, in which the architectural bureaus of Russia, France, England and Germany take part.

A night club was set up at the former Arma plant in the Kursk station, at the October paper factory - PROEKT_FABRIKA exhibition hall, in the shops of the Red Rose rose weaving center - the Art Play design center, in the building of the Trekhgornaya Manufactory in Krasnaya Presnya - business center.

Potential objects may be the Khamovniki beer factory and the hull of the Serp i Molot plant in Lefortovo, industrial premises in Zamoskvorechye, Novoslobodskaya, Shabolovka and Krasnaya Presnya.

Loft Project ETAGI (multifunctional cultural center of contemporary art in St. Petersburg) was opened in 2007 by the exhibition of Andrew Logan and Irene Kuksenate in the gallery "Globus" (5th floor) and was the first in St. Petersburg loft. It is located on five floors of the former Smolninsky bread-baking plant at Ligovsky prospect, 74 .

"Winery" (the center of contemporary art in Moscow) was opened in 2007. It is located on the territory of the former brewery (later - the winery) "Moscow Bavaria". 
Unlike the purely aesthetic perception of artists, architects and builders understand that the processes of designing lofts and preparing the reconstruction of factory buildings and buildings, as well as erection and reorganization, must be quantified both in terms of their quality and in terms of their effectiveness Subsequent functioning. In the process of such an evaluation, it is advisable to apply Academician Chulkov V.O., developed by the scientific school "Infographic foundations of functional systems". Star infographic models for evaluating the feasibility of reorganization.

Consider the definition of a complex indicator of the effectiveness of the functioning of the Loft room on the basis of star infographic models.

The integrated performance indicator organizational and technological operational reliability (OTOR) of the Loft room, which is determined with the help of stellar infographic models, makes it possible to prove arguably the necessity or absence of the need to reorganize the former industrial building.

It is necessary to structure the territory of the former industrial building into functional zones and examine in detail the object of evaluation. SNiP II-89-90 * "General plans of industrial enterprises" distinguishes between different functional areas (pre-factory, production, subsidiary and warehouse). Each of these functional areas has estimated characteristics that are subjected to analysis to establish the level of organizational and technological reliability of their operation. Along with the criterion, there is the concept of "restriction", which is close in its purpose to the criterion and complements it. The methodological approach of justification for the formation of a system of criteria and restrictions is presented in the diagram (figure 1).

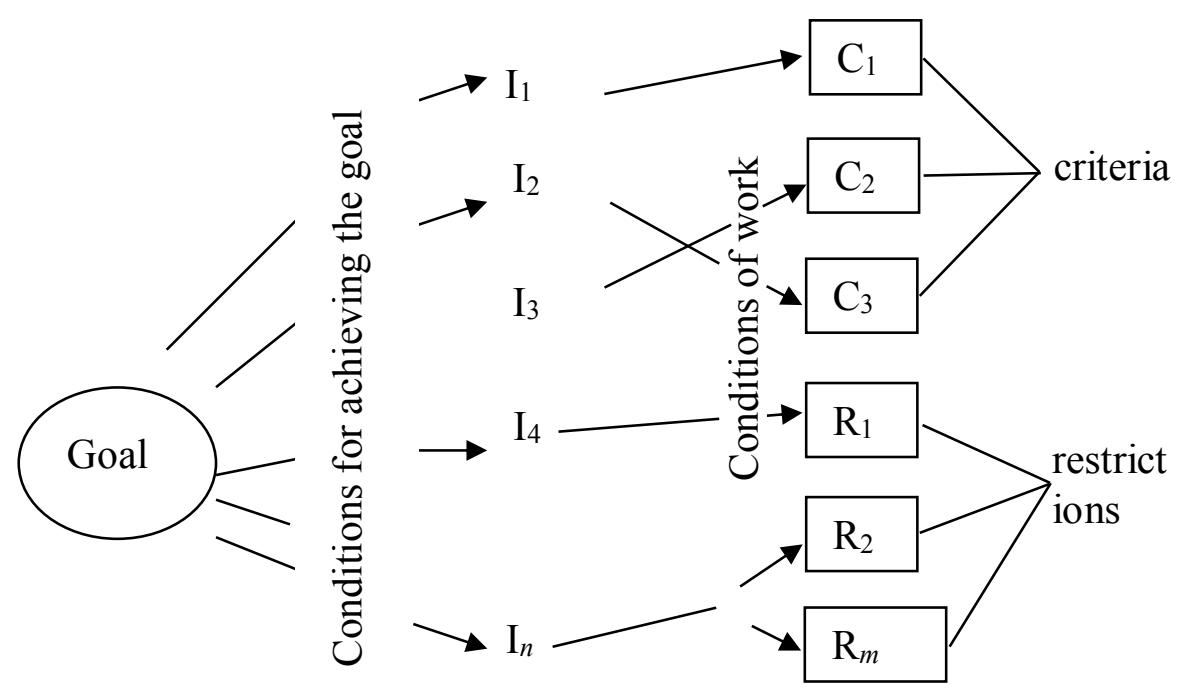

Fig. 1. The diagram of forming a system of criteria and restrictions.

To be able to compare the parameters of the assessment of functional zones, it is necessary to move from their absolute values to relative values [10]. To this end, «... for each indicator, the minimum and maximum numerical values of the indicator are revealed. The value of the interval from the minimum (taken as zero) to the maximum value (taken as a unit) of the indicator is the estimated interval for this indicator. Each current value of the indicator in this interval is referred to the value of this interval, obtaining a relative value of this current indicator in fractions or in percentage. The maximum value of the indicator value, taken as a unit, is considered the standard (maximum possible) value of this indicator. Then we build a proportion where the reference value of the parameter is taken as 
$100 \%$, and the real level for $\mathrm{X}$, and in accordance with the accepted indicators, reveal the actual level of the OTOR of the indicator under study » [Gazaryan R.K., Chulkov V.O., 2010].

\section{Discussion}

Using the above-described proportion for each indicator of the functional area estimation, determine the level of the OTOR of the evaluation indicators and construct a star infographic model in which the number of axes originating from the point "zero" corresponds to the number of parameters characterizing the specific functional zone. Valuation parameters are ranked according to their tendency to centripetal and centrifugal. To determine the level of OTOR of one functional zone, two infographic star-shaped models must be constructed, one of which is constructed by centripetal indicators and the other by centrifugal indicators [models Chulkov V.O. and Ghazaryan R.K. for the weaving factory "Red Rose" will be analyzed in subsequent works]. A number of researchers are attempting to build a complete Concept-Strategy scheme (for example, the interpretation of Kozyrev, 2012, figure 2). As an example, we considered the production zone Star model of the OTOR level of an industrial building that is being converted into a Loft room (Figure 3) with the corresponding evaluation parameters (Table 1) and (Table 2).

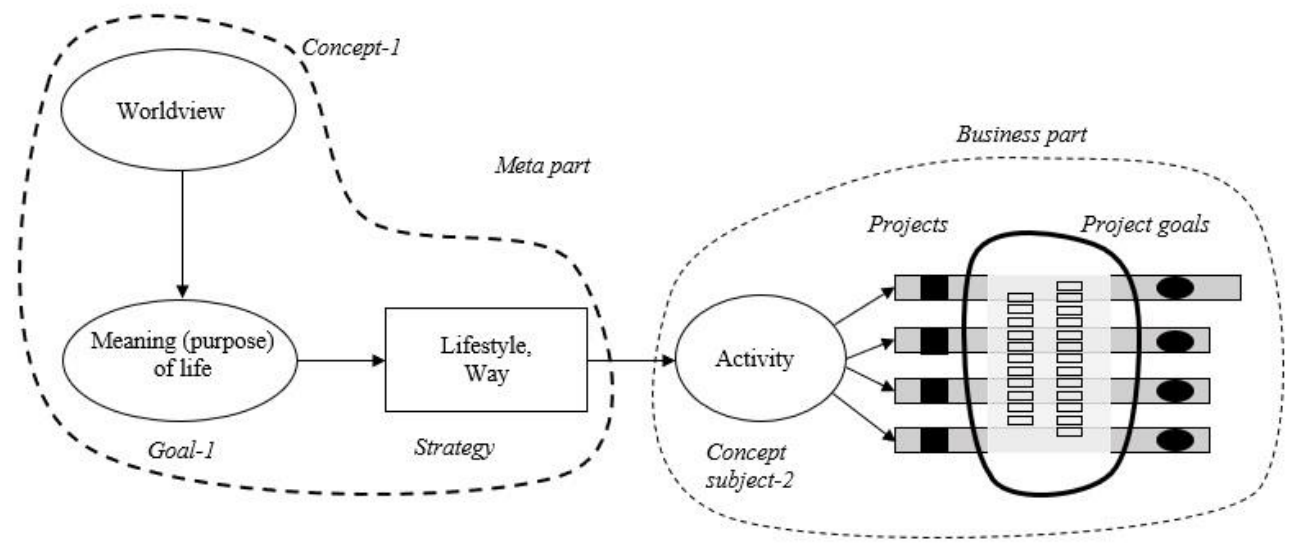

Fig. 2. Complete Concept-Strategy scheme (by I. Kozyrev, www.business-gazeta.ru, 2012).

This means that the questionnaires are submitted to scientific experts in order to express an opinion on the degree of its effectiveness in obtaining information, which the scientific researcher would like to collect, i.e. by comparing the subject of the scientific research with the questions that the researcher asks in the form of the questionnaire. The researcher can also use questionnaires that were formulated by previous researchers on the same topic of scientific research with the addition of amendments that he considers appropriate in order to transfer the research into a positive approach.

Table 1. Some indicators of the level of OTOR. 
N Functional zones of the industrial enterprise

2 Productive zone
Indicators of the level of the OTNF of the study zone

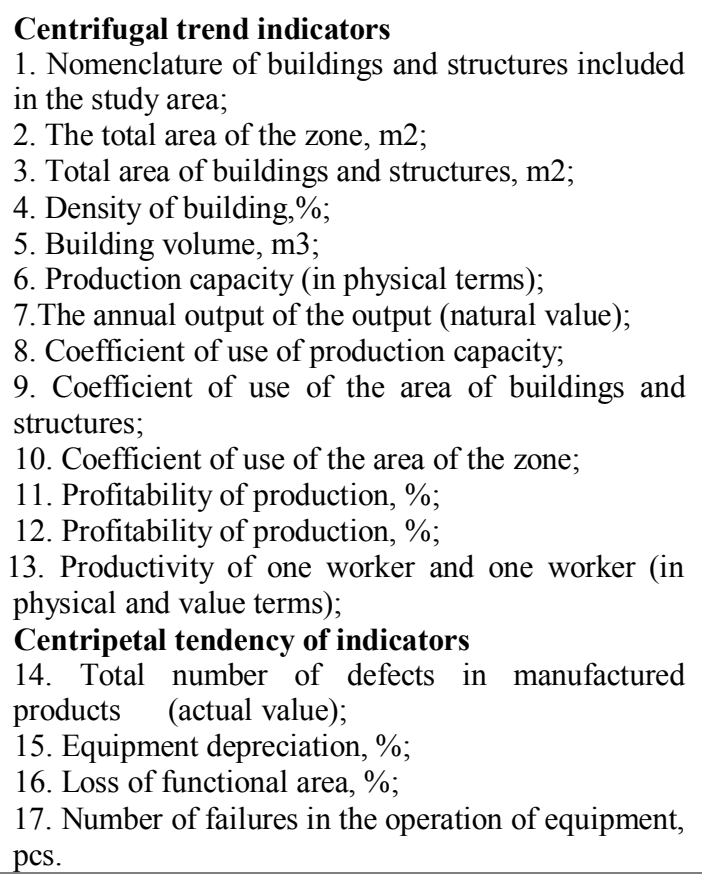

The number of axes on the star infographic model corresponds to the number of evaluation parameters.

On each of the axes of the model, the reference values of the valuation index (one) and the actual values of the evaluation criterion in relative units are plotted. As a result, we obtain a polygonal star infographic model (Figure 3) where the shaded polygon is a broken line connecting the actual values of the OTOR zone level by specific parameters, and the outer contour is the maximum possible values of the functional zone evaluation indicators.

For clarity, as an example, the model of integral estimation of the OTOR of the production zone for the centripetal and centrifugal trend of indicators is given. For each of the constructed models, it is graphically possible to draw a conclusion about which evaluation indicators need reorganization and adjustment of the OTNF to the optimal values. The optimal corridor for centripetal indices is $0-0.2$, and for centrifugal $0.8-1$, therefore, a corridor of discrepancies in the indices in $20 \%$ of the actual state of the functional zone and the compared value is given.

Then we determine the level of organizational and technological reliability of functioning in accordance with the trend of the evaluation indicators. We correlate (Figure 3) the area of polygons with actual and reference values, where $S \varphi$. - the area of the shaded polygon with the actual OTOR level, Set. - area of a polygon with reference values of the OTOR level [Star model of the OTOR level of the production zone - centrifugal trend of indicators, and centripetal tendency of indicators - models built by Chulkov V.O. and Ghazaryan R.K. for the weaving factory "Red Rose"]. As a result of the analysis, we determine the level of OTOR of the entire functional area, which combines centripetal and centrifugal indicators. To do this, we use formula (1), which is necessary for determining the average values [2]. 


$$
\text { OTOR production zone }=\frac{\sqrt{\begin{array}{c}
\text { OTORcentrifical }+ \text { OTORcentripetal } \\
\text { indicators }
\end{array}}}{n},
$$

where: $n$ is the number of indicators with heterogeneous tendencies, in general $n=2$.

For each of the functional zones, we determine the level of organizational and technological operational reliability and postpone these values on the OTOR model of the entire building, subject to reconstruction and conversion to the Loft premises. The number of axes of such a model corresponds to the number of functional zones (in the general case there may be four or more).

The obtained values of the OTOR level of the functional zones and the industrial enterprise are normalized in accordance with the law of the normal Gaussian distribution.

The optimal level of OTOR is the corridor of values from 0.45 to 0.55 in relative units.

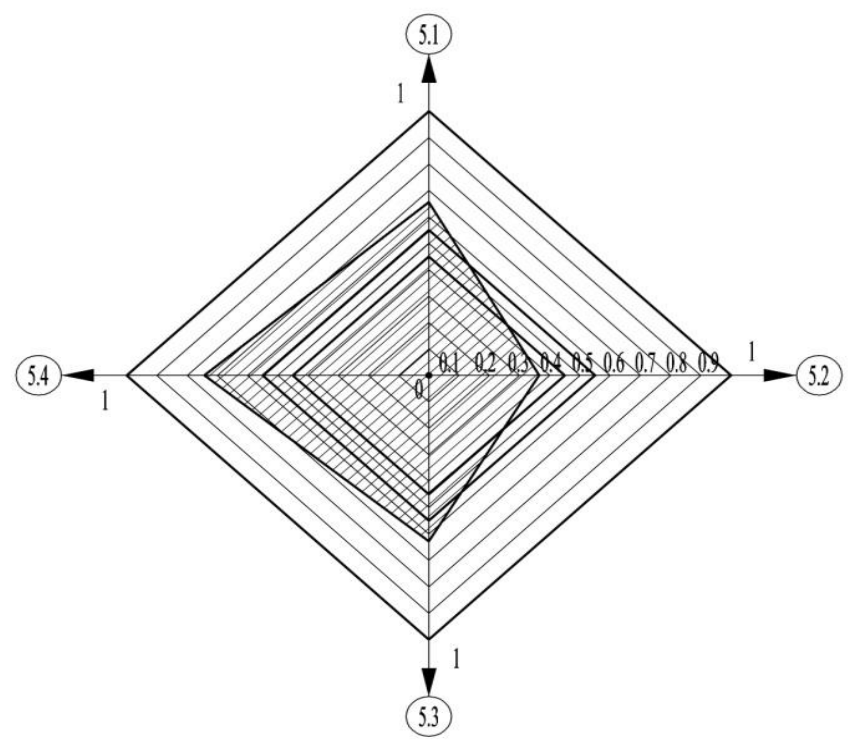

Fig. 3. Star model of the OTOR level of an industrial building that is being converted into a Loft room.

As an example, (Figure 3) presents an infographic star model of the OTOR level of an industrial building that is intended for conversion to a Loft.

On the model (Figure 3), it is possible to graphically determine which vertices of the shaded polygon lie in suboptimal limits (that is, which functional zones need reorganization).

Table 2. The names of the axes of the model (Figure 3) of the level of the OTOR of an industrial building. 


\section{N Description of functional zones}

\begin{tabular}{cl}
\hline $\mathbf{5 . 1}$ & Pre-factory zone \\
\hline $\mathbf{5 . 2}$ & Production zone \\
\hline $\mathbf{5 . 3}$ & Utility zone \\
\hline $\mathbf{5 . 4}$ & Warehouse zone \\
\hline
\end{tabular}

\section{5}

\section{Conclusions}

As a result of the study, several conclusions can be drawn of retrivationas as a type of highrise construction:

1. If the OTNF level of an industrial building, which is being converted into a Loft, falls outside the optimal corridor of values from 0.45 to 0.55 , the object under investigation can be reconstructed (if there is a customer for such a reconstruction).

2. To evaluate the level of the OTP of an industrial building that is being converted into a Loft, it is possible to apply both planar concentric models and multi-layer ones, using convolution and sweep methods to realize the assigned tasks [1].

3. In the construction industry there is a sufficiently large number of multiparameter tasks that require a systematic approach and the definition of a single integrated indicator of the effectiveness of the operation. These tasks can be solved using a variety of approaches.

4. One of such approaches, as the method of integral evaluation based on stellar infographic models, is considered above.

5. In parallel with this approach, other approaches can be used (for example, the definition of a generalized indicator of environmental load [3], a complex index of efficiency (efficiency index) of a construction organization, and others).

\section{References}

1. A.A. Volkov, V.O. Chulkov, G.O. Chulkov, R.R. Kazaryan, O.N. Kyzina, AMR 1065-1069, 2401-2404 (2015). DOI: 10.4028/www.scientific.net/AMR.10651069.2401.

2. A.A. Volkov, V.O. Chulkov, G.O. Chulkov, R.R. Kazaryan, O.N. Kyzina, AMR 1065-1069, 2405-2408 (2015). DOI: 10.4028/www.scientific.net/AMR.10651069.2405.

3. A.A. Volkov, V.O. Chulkov, G.O. Chulkov, R.R. Kazaryan, O.N. Kyzina, AMR 1065-1069, 2409-2412 (2015). DOI: 10.4028/www.scientific.net/AMR.10651069.2409.

4. V.V. Chulkov, A.A. Volkov, O.N. Kyzina, R.K. Gazaryan, AMR 1065-1069, 25662569 (2015). DOI: 10.4028/www.scientific.net/AMR.1065-1069.2566.

5. M. Zharova, S. Shirokova, O. Rostova, E3S Web Conf. 110, 02033 (2019). DOI: https://doi.org/10.1051/e3sconf/201911002033.

6. E. Kouzmina, V. Okrepilov, E3S Web Conf. 110, 02034 (2019). DOI: https://doi.org/10.1051/e3sconf/201911002034.

7. D. Abdrakhmanova, E. Karasik, L.Safiullin, A. Scharonova, E3S Web Conf., 110, 02035 (2019). DOI: https://doi.org/10.1051/e3sconf/201911002035. 
8. Z. Adamanova, S. Lukyanova, L.Safiullin, O.Medvedeva, E3S Web Conf., 110, 02036 (2019). DOI: https://doi.org/10.1051/e3sconf/201911002036.

9. D. Skripnuk, K. Kikkas, E. Romashkina, E3S Web Conf., 110, 02037 (2019). DOI: https://doi.org/10.1051/e3sconf/201911002037.

10. A. Ajupov, D. Kurmanova, N. Bagautdinova, L. Kurmanova, E3S Web Conf., 110, 02038 (2019). DOI: https://doi.org/10.1051/e3sconf/201911002038.

11. N. Safiullin, B. Safiullin, O. Schnaider, E3S Web Conf., 110, 02039 (2019). DOI: https://doi.org/10.1051/e3sconf/201911002039.

12. A. Ajupov, A. Sherstobitova, S. Syrotiuk, A. Karataev, E3S Web Conf., 110, 02040 (2019). DOI: https://doi.org/10.1051/e3sconf/201911002040.

13. I. Zaychenko, N. Grashchenko, T. Saurenko, V. Anisimov, E. Anisimov, V. Zhigulin, E3S Web Conf., 110,02041 (2019). DOI: https://doi.org/10.1051/e3sconf/201911002041.

14. A. Akhmadullina, S. Vasilyeva, T. Yakovleva, S. Vopiyashina, R. Kraineva, E3S Web Conf., DOI: https://doi.org/10.1051/e3sconf/201911002042.

(2019).

15. R.R. Kazaryan, MATEC Web Conf., 193, 01009 (2018).

16. R.R. Kazaryan, MATEC Web Conf., 193, 04023 (2018).

17. R.R. Kazaryan, MATEC Web Conf., 239, 02006 (2018).

18. R.R. Kazaryan, MATEC Web Conf., 170, 05001 (2018).

19. M. Kuziakina, D. Gura, D. Zverok, E3S Web of Conferences 138, 02004 (2019). DOI: $10.1051 / \mathrm{e} 3$ sconf $/ 201913802004$ 